\title{
Transformations, Treatment, and Prevention of Water Pollutants
}

\author{
José L. Campos, ${ }^{1}$ Anuska Mosquera-Corral, ${ }^{2}$ Ángeles Val del Río, ${ }^{2}$ and Marisol Belmonte ${ }^{3,4}$ \\ ${ }^{1}$ Facultad de Ingeniería y Ciencias, Universidad Adolfo Ibáñez, Avenida Padre Hurtado 750, 2520000 Viña del Mar, Chile \\ ${ }^{2}$ Department of Chemical Engineering, School of Engineering, University of Santiago de Compostela, Rua Lope Gómez de Marzoa s/n, \\ 15782 Santiago de Compostela, Spain \\ ${ }^{3}$ Department of Environment, Faculty of Engineering, University of Playa Ancha, Avenida Leopoldo Carvallo 270, \\ 2340000 Valparaíso, Chile \\ ${ }^{4}$ School of Biochemical Engineering, Pontifical Catholic University of Valparaíso, Avenida Brasil 2085, 2340000 Valparaíso, Chile
}

Correspondence should be addressed to José L. Campos; jluis.campos@uai.cl

Received 30 June 2016; Accepted 30 June 2016

Copyright ( $\odot 2016$ José L. Campos et al. This is an open access article distributed under the Creative Commons Attribution License, which permits unrestricted use, distribution, and reproduction in any medium, provided the original work is properly cited.

If we hear the word "Earth" the first thing that comes to our mind is the image of a big blue ball. This image often leads to thinking that water is an unlimited resource but it really is not, at least, with the quality needed to support human life. We need to be aware that water is a limited resource, since our current way of life along with population growth makes us consume water at a higher rate than nature itself can supply us. To these factors, we must add climate change and pollution which give more uncertainty to the current scenario of water resources. Therefore, it is necessary to implement actions that take into account an integrated management of the water cycle and one of them would be the protection of resources by maximizing the collection of wastewater generated and giving further treatment to prevent possible deterioration of the quality of the receiving surface water and groundwater.

Human activities such as the use of fossil oil, mining, and agriculture are influencing water quality. Nutrients from fertiliser and from sanitation systems are released directly into aquatic ecosystems, and also pesticides, industrial pollutants, or medical substances eventually end up in water. This causes the accumulation of these substances in the water cycle which provokes pollution problems affecting ecosystems and human health. Therefore, the knowledge of the chemical/biochemical transformations of these pollutants in water is very important in order to determine their possible noxious effects or, even, the better way to remove them.
In this special issue, we aimed to report the last developments concerned with transformations, treatment, and prevention of water pollutants. The selected seven papers may not fully cover the topic of this special issue, since they are mainly related to the pollutant treatment. However, they show how current research in wastewater treatment is mainly focused on providing feasible and cheap alternatives to remove pollutants at high efficiency.

Six of these papers are focused on removing complex organic compounds and heavy metals from wastewater by using low-cost absorbents, while one paper provides a new control system for WWTPs to obtain an effluent with a better quality.

In one of the papers, $\mathrm{X}$. Mi et al. proposed the use of raw cornstalk biochar modified by cetyltrimethylammonium bromide (CTAB) as a composite adsorbent for removing negatively charged pollutants. They achieved removal efficiencies up to $99.7 \%$ for anionic dye Orange II. On the other hand, cassava peel chemically modified with $\mathrm{H}_{2} \mathrm{O}_{2}, \mathrm{H}_{2} \mathrm{SO}_{4}$, and $\mathrm{NaOH}$ could be an excellent adsorbent of $\mathrm{Cd}^{+2}, \mathrm{~Pb}^{+2}$, and $\mathrm{Cr}^{+3}$ as $\mathrm{D}$. Schwantes et al. show in another paper of this special issue.

A.-R. A. Giwa et al. tested the biosorption of acid blue 161 dye onto sawdust of locust bean (Parkia biglobosa) in single, binary, and ternary dye systems with rhodamine B and methylene blue dyes in aqueous solution. They found that the presence of rhodamine $B$ and methylene blue had a synergetic effect on the maximum monolayer capacity of the adsorbent 
for acid blue 161 dye. Wasted black tea can be applied to wastewaters to remove both nickel and zinc as was proposed by A. Malakahmad et al. These authors show potential of this material to be applied as an effective sorbent due to high concentrations of carbon and calcium and high porosity and availability of functional groups. In the optimum conditions, maximum capacity of wasted black tea could reach up to $90.91 \mathrm{mg}-\mathrm{Ni}^{+2} / \mathrm{g}$ adsorbent and $166.67 \mathrm{mg}-\mathrm{Zn}^{+2} / \mathrm{g}$ adsorbent.

The hybrid processes, which are based on the synergic combination of two technologies, are gaining more importance every day. In the work of S. S. K. Bekaroglu et al., the combination of the adsorptive and catalytic properties of iron oxide surfaces in a hybrid process using hydrogen peroxide and iron oxide-coated pumice particles was used to remove natural organic matter (NOM) in water. The results obtained showed that the process was effective in removing UV280absorbing NOM fractions and controlling of disinfection byproduct formation.

In one of the papers, F. Gönen and E. Köylü studied the adsorptive removal of telon blue AGLF (TB AGLF) from aqueous solution using sunflower pulp. They determined the effects of $\mathrm{pH}$, adsorbent dose, temperature, and initial dye concentration on the adsorption capacity and the removal efficiency of telon blue AGLF. Experimental results showed that sunflower pulp was excellent agroindustrial adsorbent with maximum dye removal efficiency of $97.2 \%$ at $100 \mathrm{mg} \mathrm{L}^{-1}$ initial dye concentration, a $\mathrm{pH}$ value of 3 , temperature of $50^{\circ} \mathrm{C}$, and $1 \mathrm{~g} \mathrm{~L}^{-1}$ of adsorbent dose.

The last contribution in this special issue is from $\mathrm{M}$. Malovanyy et al. who proposed the aeration strategy based on the measurement of the ammonium concentration instead of the dissolved oxygen concentration. These authors observed that the ammonium-based control was superior to the control strategy with the dissolved oxygen concentration in terms of ammonium discharge fluctuations but has higher aeration requirement.

\section{Acknowledgments}

The guest editors wish to express their thanks to all authors for their contributions as well as the reviewers who through their efforts and time have helped improve the quality of the manuscripts.

José L. Campos

Anuska Mosquera-Corral

Ángeles Val del Río

Marisol Belmonte 

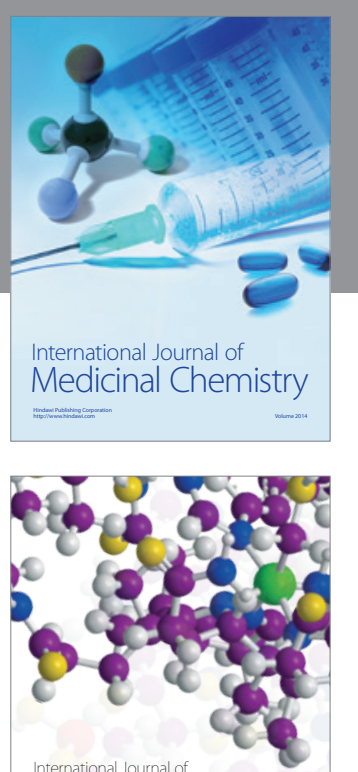

Carbohydrate Chemistry

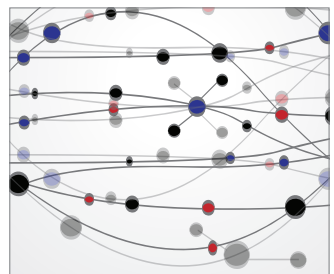

The Scientific World Journal
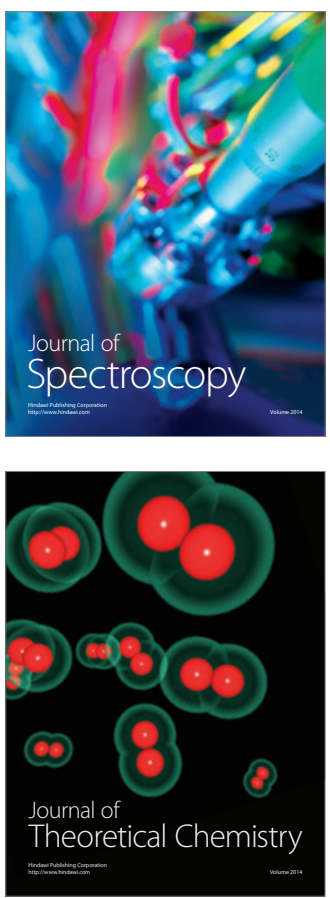
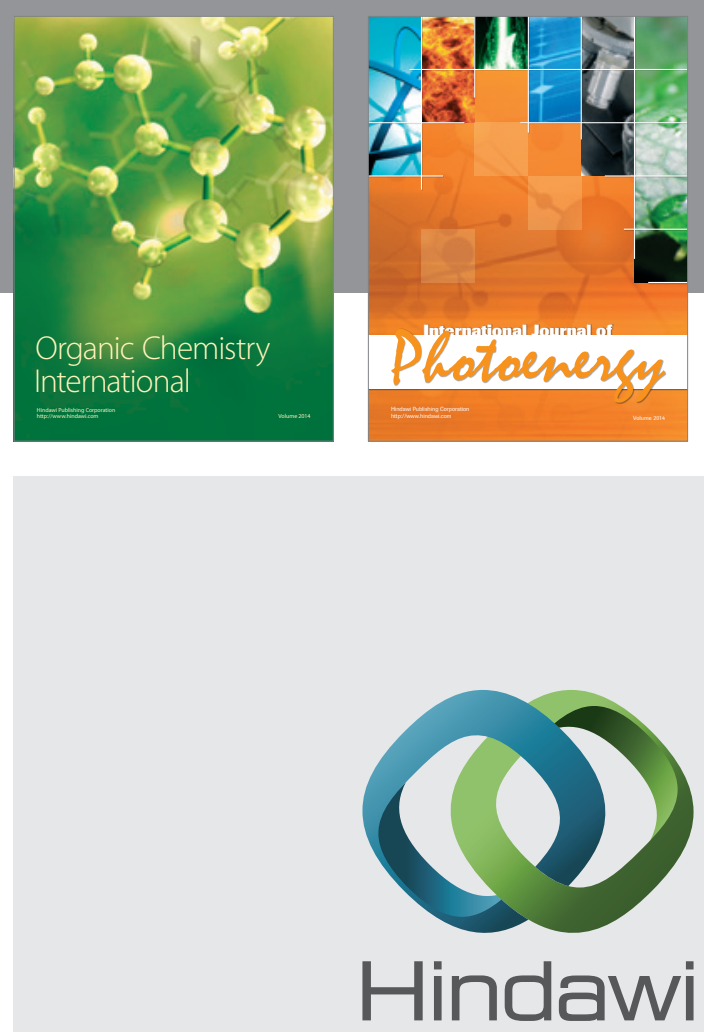

Submit your manuscripts at

http://www.hindawi.com

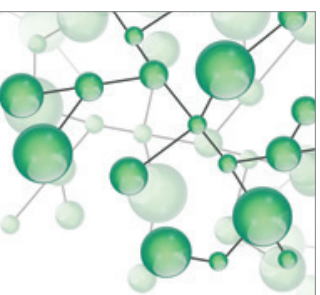

International Journal of

Inorganic Chemistry

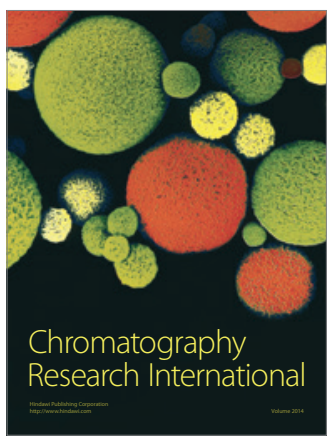

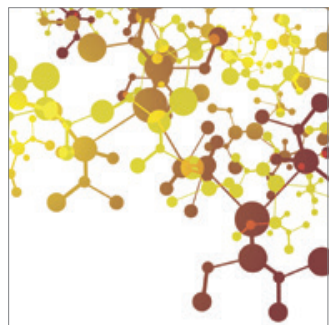

Applied Chemistry
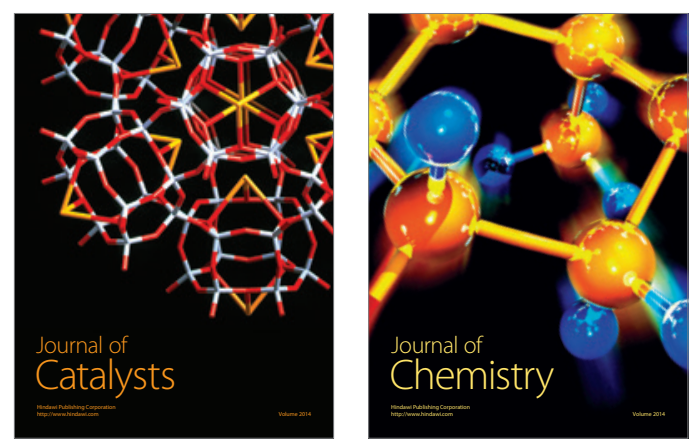
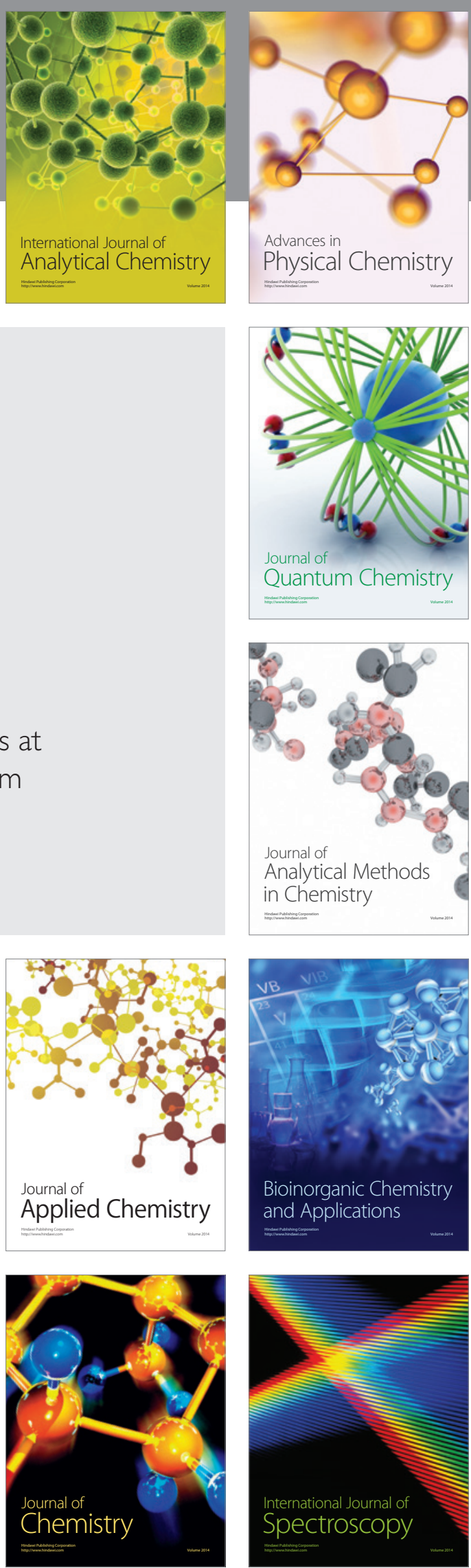